\title{
Leveraging Technological Capabilities for Competitive Advantages: Giving Samsung Way a Glance
}

\author{
Nader Arvand \\ International Business School (IBS), UTM, Malaysia
}

\begin{abstract}
One of the serious problems confronting developing and developed economies is the management and preservation of energy sources. While modern technologies (systems, tools, and machines) are being developed, demands for computing and telecommunication systems grow to adapt people with new business environment. Current electricity users comprise new generation of heavy electricity users such as portable electronic systems which have been boosted rapidly over span of happening years, whereas their main energy sources such as batteries have been improved in energy density and capacity at a much slower pace.
\end{abstract}

Keywords: Battery, Technology, Competitive advantage

\section{Introduction}

Transition from fixed-lined devices to wireless, had provided users with convenience of moving small computers (laptops) and changing their places before modern mobile handsets invented. They have made unlimited mobility available for devices equipped by internet applications, business and computer software, and eye-catching point is that you have all your data, mail boxes, and business in a tiny device fitting your pocket. Unfortunately, the battery performance has not been improved at a desirable pace [1].

To fully grasp the small-scale mobile device users, companies need to more effectively allocate their resources and pursue market-driven strategies in terms of technology management and innovation. Convergent technology developed in smartphones currently comprises computing, navigation, imaging, and media applications, however; only the computing features have been considered by consumers to be useful and good quite enough which motivates them to pay [2].

The question raised here is whether the low speed of improvement in the cell phone battery industry is caused by falling or low demand of customers (user behaviour), or by technological obstacles that make it difficult for technical experts to achieve creating high-capacity batteries. I study cell phone users' behaviour by the questionnaire approach with $\mathrm{N}=426$ (small sample size) showing that customers do not consider the battery life time as their first three priorities when they buy a cell phone.

On the technical side, developing more energy-efficient handsets which work well without wasting energy is the major engineering difficulty [1]. The problem with batteries is posed where more "mAh"(the unit for battery life time measurement describing the total amount of energy a battery charges up at each recharging) is better since it gives you higher battery capacity, but likely the battery is heavier and bigger than the others.

Up until this point, overcoming mentioned problem with batteries necessitate producing larger and heavier batteries simultaneously. The amount of electric energy consumed with a cell phone is being raised where features, applications, and networks provided by a cell phone are increasing. Therefore, there are more critical situations in which battery running out of power faces, especially for smartphone users.

The satisfactory solution that electronics engineering experts come with is Dynamic Power Management (DPM) technology which refers to selective shut-off or slow-down of the idle or underutilized components [3]. However, this technique works quite effectively when the mobile device does not support communication capabilities including 3G cellular network and Wi-Fi connection [4].

Burgelman, Christensen, and Wheelwright (2009) [5] found that the larger existence gap between the company's own technological knowledge and those for customers of that particular technology results in higher prices for a product carries mentioned technology.

The purpose of this article is to recognize and estimate the own knowledge of electronics companies in terms of improving battery lifetime, then to compare it with customers' knowledge which has been analysed based on primary data gathered, in order to figure out how the existing gap is large. Then, if it can be proved that giant electronics companies have already gained the information and technology of manufacturing longer life-time smartphone batteries, so the logic behind their decision on not bring it to the market and commercialize it is clarified. 


\section{Literature review}

One of the earliest previous studies on mobile phones published by Wright et al. (1998) [6], who carried out a life-cycle energy research on a pilot mobile phone in Sweden and United Kingdom in 1997. They arrived at a conclusion that in terms of energy perspective, it would be more environmentally friendly to recycle mobile phones whereas costs might limit. Thus it seems the longer mobile phone life cycle leads to less material and waste recycling costs while could indirectly ease the pressure exerted by environmental groups on mobile handset industry.

Meskers and Hageluken (2009) [7] estimated that over 40 elements are parts of mobile phones overall, including copper (a soft reddish-brown metal that allows electricity and heat to pass through it easily) and tin (a soft silver-white metal that is used to cover and protect iron and steel), special metal elements including indium and antimony, and precious metals such as palladium (a soft silver-white metal that is often combined with gold, and used to cover an object with a very thin layer of metal) and gold. Metals account for around $23 \%$ of a cell phone weight, where plastics form $50 \%$ of its weight.

Assessing cell phone market shows cell phones have fairly short product life cycle, without being affected or influenced by brand names or models. Numerous users see their cell phones as products which are no longer useful within little over a year, because new models are being marketed with short shelf life. Thus, mobile phones, in terms of mass and volume, are most valuable electronic materials founded in waste streams [8]. The subject can be donated more attention whilst cash pay-outs are substantial when it comes to setting up the project of treating used plastics and metals so they can be used again.

While the real problem is being faced in industry and market sides, the solution can be rooted in a technology advances the cell phone life cycle or rather the long-life battery.

Energy consumption of advanced cell phones is being generated by computing and connectivity applications, therefore, studies have viewed the energy consumption measurement from different perspectives including wireless fidelity connections [9], GPS applications [10], VoIP systems [11], video streaming and media applications and data managing algorithms [12], however; consumer feelings and opinions have not been mentioned on aforementioned papers. Mobile phone users' attitudes with regard to energy consumption levels and savings have been examined by Rahmati and Zhong (2008) [13] and probed by Heikkinen and Nurminen (2009) [14].

This paper reports the concerns and expectations users have regarding applications, energy consumption and whether or not Samsung Electronics has met this demand with current products offered.

\section{Methodology}

The study will specify criteria that customers use to judge portable devices (smartphones) and make decisions about their purchase. Their opinions (data) were collected by asking them to fill questionnaires. Respondents are comprised of experts in electronics, business students (MBA students of International Business School of University Technology Malaysia), and the public, all own and use smartphones.

Meanwhile, the study is aimed at exploring the investment development path of Samsung Electronics and how she adapts herself in terms of customers' preferences -determined by questionnaire- and advanced cell phone batteries, by collecting and reporting secondary data.

\section{IV.I Limitations}

\section{Analysis}

The limitations have been placed on this analysis by the public where they answered questions posed in a way showing their commitment to the technological norms, whereas they did not have the know-how to explain why they think a particular technical feature of their cell phones has the quality of being important to them. Thus, all answers given to open-ended questions represent the opinions of technologically aware segment of users, but not all respondents.

\section{IV.II Focus}

According to the small scale of the sample size, best endeavours have been made to looking for how respondents think rather than how many users think in a certain way, therefore, the majority of questions left open for more suggestions. The first three priorities of users when buying a cell phone, User's knowledge and concerns over battery life time and capacity, and why they own Samsung brand or not are main subjects that need to be discussed and deal with in this analysis. 
Leveraging Technological Capabilities for Competitive Advantages: Giving Samsung Way a Glance

\section{IV.III Data categorization}

Table.1 (Rates of return)

\begin{tabular}{|c|c|c|c|c|}
\hline Questionnaires & $\begin{array}{l}\text { Electronics } \\
\text { Experts }\end{array}$ & MBAs & The Public & Total \\
\hline Distributed & 115 & 66 & 245 & 426 \\
\hline Returned & 98 & 66 & 164 & 328 \\
\hline Percentage & $85.2 \%$ & $100 \%$ & $66.9 \%$ & $77 \%$ \\
\hline
\end{tabular}

Table.2 (Respondent's profile)

\begin{tabular}{l|l|l}
\hline Profile & Male & 238 \\
\hline Gender & Female & 188 \\
\hline & Total & 426 \\
\hline Age Group & $\geq 45$ & 67 \\
\hline & between 31-44 & 48 \\
\hline & $<31, \geq 25$ & 311 \\
\hline Status & Total & 426 \\
& Employed & $51.4 \%$ \\
& Student & $42.8 \%$ \\
\hline A Samsung user & Other & $5.8 \%$ \\
\hline & yes & 48 \\
& no & 378
\end{tabular}

Table.3 (Responses)

\begin{tabular}{lll}
\hline \multicolumn{2}{l}{ Questions } & Categories of Responses \\
\hline $\mathbf{1}$ & How much battery life do you & 1.1 More than a day for all respondents: Music fans, Internet heavy- \\
need? & users, Talkative users (+24h/ not on standby position)
\end{tabular}




\section{IV.IV Patterns and connections}

Aforementioned categorizations include people with various educational levels, their desire for a cell phone's features, and their standpoints of Samsung brand. The technical knowledge about the cell phone battery varies subtly among respondents and naturally is in harmony with electronics expertise required for responding. The interesting point observed among 29 0ut of 30 student respondents is the misconception or relative lack of general information, when it comes to translating battery labels. This is similar to responses drawn from the public. Thus, the users' technology knowledge regarding cell phones' batteries shows no ascending trend moving from ordinary people to master students.

Customers' highest ranking desires and wants of a cellular phone features differ significantly between respondents. The formal education level goes up, regardless of the specialization, the way that desirable features' priorities are arranged differs, so that "Durability" is first, the "Battery life-time" is second, and the "Brand" ranked thirdly. In reverse and a bit different order, the "Look", "Durability", and "Brand" rank as the first three main favourable features distinguished of a smartphone by the public.

A Korean company that is best known for making and marketing electronic goods- Samsung is the popular brand among the public as they are satisfied with its smartphones' looks. Samsung product planning in terms of features has attracted the public attention by its smartphones' appearance successfully, whereas only 17 out of 181 respondents (66 masters of business accompanied by115 electronic experts who own smartphones) say they use Samsung smartphone for being satisfied with its durability. To complicate matters for Samsung, no literate Samsung smartphone users voted for satisfying battery life time.

When the question" How much battery life do you need?" was put to respondents, they made a choice of "longer the better" meaning more than 24 working hours to them, practically, more than what is being provided by smartphone batteries.

\section{IV.V Interpretation}

The relations between users' technical knowledge, their desires regarding smartphone features, and their battery lifetime need contain apparent contradiction. Where present smartphones batteries' lifetime causes the inconvenience of recharging regularly and all respondents, without being influenced by their technical knowledge, stress this clear need, the query necessitates to be answered is about why ever they still give low priority to batteries when buying a smartphone.

Following table shows the top priority among list of features in terms of users' viewpoints.

Table.4 (Users' priorities)

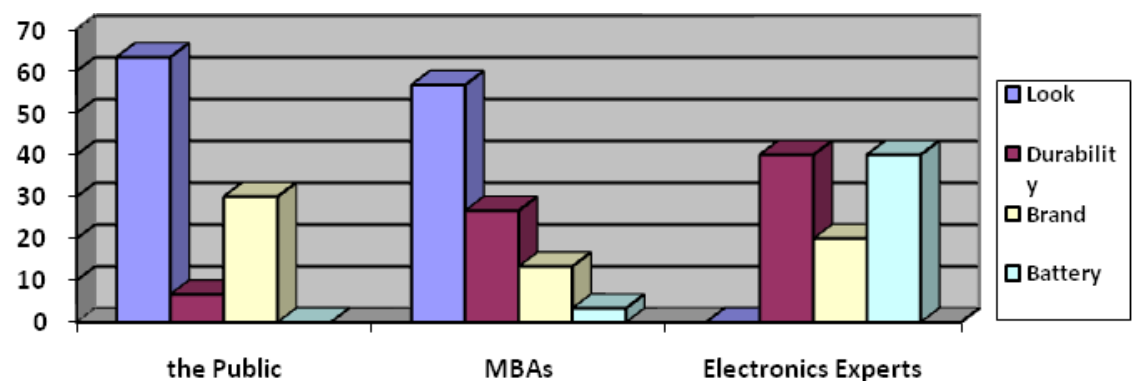

\section{V.I Battery Life}

\section{Discussion}

\section{V.I.I Do smartphone users allow new applications eat battery life?}

New computer software with the capability of being run online demands a considerable supply of electricity and is the main battery life reducible. The Prospect Theory developed by Kahneman and Tversky (1979) [15] explains the people assessment of changes as they make judgment on new things becoming different compared to a reference point. Based on this hypothesis, especially when it places emphasis on people's nonlinear attitudes with regard to this issue, users do not allow new applications reduce their battery life time.

But, in questionnaire, $87 \%$ of respondents rephrased their smartphone usage as the clear preference for internet access rather than 4 day handset's battery life. Others (13\%) highlighted a sharp contrast between appearance of mobile phones and mobile phones that also works as a personal digital assistant (PDA), as their proof of a smartphone purchase. 
Leveraging Technological Capabilities for Competitive Advantages: Giving Samsung Way a Glance

\section{V.I.II Are users aware of power-saving methods?}

Largest power consumer items of a smartphone are but not limited to display brightness, automatic discovery of Wi-Fi, probing for external devices via Bluetooth, Rich Site Summary (RSS: software that tells an Internet user when a website has new information on it), and status update in social networks. The survey carried out in China by Rahmati and Zhong (2008) [14] revealed that many users were not realizing or rather noticing that their smartphones are provided with power-setting options. As the supporting documentation, during this study, $14.3 \%$ of respondents who have been classified under electronics experts were aware of the availability of power-setting options, and more importantly, how to make more energy efficient adjustments.

Student and the public placed the blame on handbooks containing a lot of information or details.

The brief discussion included is whether the low speed of improvement in the cell phone battery industry is caused by falling or low demand of customers (user behaviour), or by technological obstacles. The preceding discussion part formed based on users' behaviour. The customers' needs and wants regarding battery lifetime have been identified as their demand grows faster than technology. If a company does especially well compared to rival firms in terms of designing and introducing next generation of smartphone batteries with longer lifetime, they can represent a competitive advantage.

\section{V.II Samsung strategies for gaining a competitive advantage V.II.I Strategies}

A component-based company, Samsung, seized the opportunity in the digital age, when her previous rival in preceding years missed out on digital music and digital television. Sony, a product-based company, who keeps her focus on technology and innovation, did not promote technological innovation and failed to catch competitive advantage in digital goods competition. Gaining ownership or increased control over distributors or retailers and looking for ownership or increased control of suppliers are vertical strategies being followed by Samsung [16].

\section{V.II.II Technology internalization}

The acquisition, alternation, and application of systems and technologies from outside the firm's logistics, can improve technological capabilities. The process is external technology sourcing and provides an opportunity to design and manufacture a self-designed and exclusive product [17].

Doing an assessment of smartphone battery improvements illustrates here that advanced battery technology is the high complexity. The Table.4.1 and 2 show the technology matrix and mode of technology internalization matrix. The technology matrix is the box formed by technological availability at low and high levels as columns, and technological complexity at high and low levels as rows. The technology internalization matrix is combined by multi-specialty and acquisition methods of core technology as its dimensions. Acquisition methods are "Buy" and "Make" as columns and the multi-specialty is at high and low level demonstrated as rows.

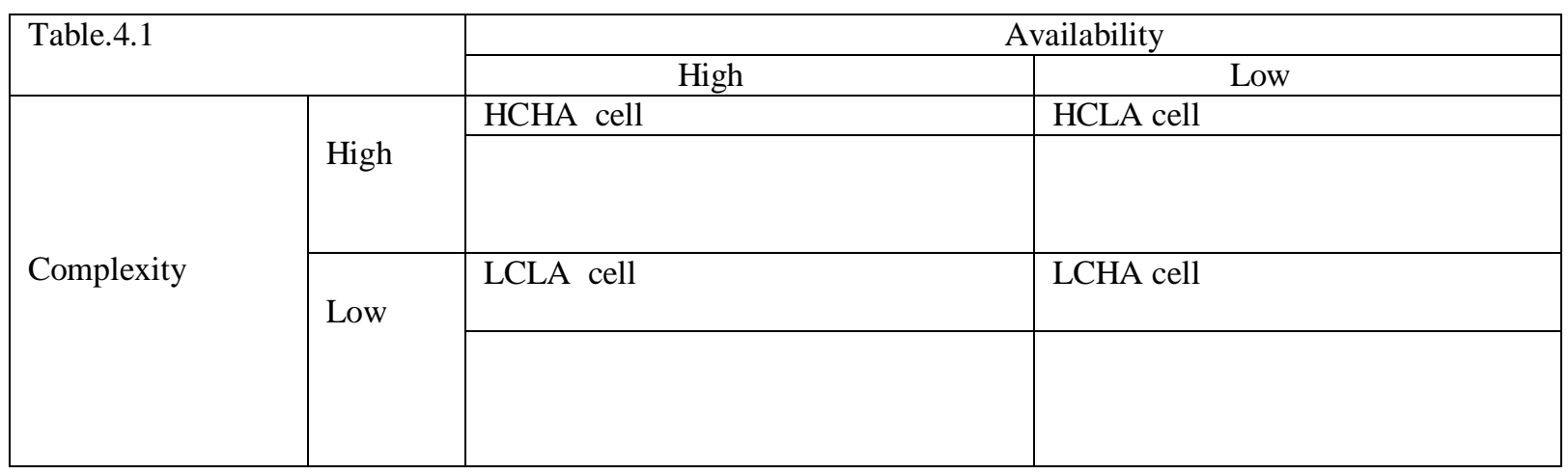

\begin{tabular}{|c|c|c|c|}
\hline \multirow{2}{*}{\multicolumn{2}{|c|}{ Table.4.2 }} & \multicolumn{2}{|l|}{ Acquisition methods of core technology } \\
\hline & & Buy & Make \\
\hline \multirow{4}{*}{ Multi- specialty } & \multirow{3}{*}{ High } & Mid-entry strategy mode & Full-scale in-house R\&D mode \\
\hline & & & \\
\hline & & Effective reverse engineering mode & Focused in-house R\&D mode \\
\hline & Low & & \\
\hline
\end{tabular}




\section{Conclusion}

Unfortunately, the battery performance has not been improved at a desirable pace [4], and the survey conducted in this study reveals that the mentioned technology is low in availability in markets. When full-scale in-house R\&D mode of acquisition methods of core technology is selected by Samsung for technologies in MLCC (Ranked as Top five in its global market share, core component for Mobile Phone), performance of technology internalization has been successful. The MLCC is categorized as high-complexity low-availability within Samsung technology matrix [18], remarkably similar to the battery technology.

The broader gap between customers and companies in terms of product technology knowledge, the higher price put up for that particular product is acceptable by market [5], thus, high investment in in-house research and development for battery technology advancement accompanied by pull marketing strategy efforts -that encourage demands- expect high return on investment within this industry while this modern technology capability could reduce recycling costs of used plastics and metals as electronic waste streams.

\section{References}

[1] Mikko, V. H., Jukka, K. N., Timo, S., \& Heikki, H. (2012). Energy efficiency of mobile handsets: Measuring user attitudes and behavior. Telematics and Informatics.

[2] Robinson, S. (2009). Cellphone energy gap: desperately seeking solutions, Strategy Analytics.

[3] Benini, L., Paleologo, G., Bogliolo, A., \& De Micheli, G. (1999). Policy optimization for dynamic power management. IEEE Trans. Computer-Aided Design, 813-833.

[4] Peng, R., \& Pedram, M. (2010). A Markovian Decision-based Approach for Extending the Lifetime of a Network of BatteryPowered Mobile Devices by Remote Processing. Low Power Electronics, 6(2).

[5] Burgelman, R., Christensen, C., \& Wheelwright, S., Strategic management of technolog and innovation.(New York: McGRAWHILL INTERNATIONAL EDITION, 2009).

[6] Wright, L. M. (1998). Mobile phone takeback and recycling: analysis of the ECTEL project. Oak Brook, Illinois, USA, IEEE, pp. 59.

[7] Meskers, C. H. (2009). Closed loop WEEE recycling? Challenges and opportunities for a global recycling society. In: Howard, S.M. (Ed.), EPD-TMS congress 2009. Proceedings of Sessions and Symposia Sponsored by the Extraction \& Processing Division (EPD) of The Minerals, Metals \& Materials Society (TMS), (pp. 1049-1054.). San Fransisco, California, USA.

[8] Ongondo, F., \& Williams, I. (2011). Greening academia: Use and disposal of mobile phones among university students. Waste Management, 1617-1634.

[9] Amitabha, G., \& Sajal K., D. (2008). Coverage and connectivity issues in wireless sensor networks. Pervasive and Mobile Computing, 303-334.

[10] Xiuxiao, Y., Jianhong, F., Hongxing, S., \& Charles, T. (2009). The application of GPS precise point positioning technology in aerial triangulation. ISPRS Journal of Photogrammetry and Remote Sensing, 541-550.

[11] Lin-huang, C., Chun-hui, S., Shih-yi, C., \& Yen-wen, L. (2010). Design and realization of ad-hoc VoIP with embedded p-SIP server. The Journal of Systems and Software, 2536-2555.

[12] Sammartino, G., Zarrelli, C., Urciuolo, V., Di Lauro, A., Di Lauro, F., Santarelli, A., et al. (2007). Effectiveness of a new decisional algorithm in managing mandibular ameloblastomas: A 10-years experience. British Journal of Oral and Maxillofacial Surgery, 306-310.

[13] Rahmati, A., \& Zhong, L. (2008). Human-battery interaction on mobile phones. Pervasive and Mobile Computing, 465-477.

[14] Heikkinen, M., \& Nurminen, J. (2009). Consumer attitudes towards different aspects of mobile peer-to-peer services. First International Conference in P2P Systems, (pp. 132-137).

[15] Kahneman, D., \& Tversky, A. (1979). Prospect theory: an analysis of decision under risk. Econometrica, 263-291.

[16] Chang, S. (2009). Sony vs. Samsung: The Inside Story of the Electronics Giants' Battle for Global Supremacy. J. Eng. Technol. Manage, 26, 215-217.

[17] Lee, J., Bae, Z., \& Choi, D. (1988). Technology development process in a developing country: a global perspective model. $R \& D$ Management, 18(3), 235-250.

[18] Gil, Y., Bong, S., \& Lee, J. (2003). Integration model of technology internalization modes and learning strategy: globally late starter Samsung's successful practices in South Korea. Technovation, 23, 333-347. 